\title{
Protocol for production of a chewable material for masticatory function tests (Optocal - Brazilian version)
}

\section{Rafael de Liz Pocztaruk(a) Luis Carlos da Fontoura Frasca ${ }^{(b)}$ Elken Gomes Rivaldo(b) Eduardo de Lima Fernandes ${ }^{(a)}$ Maria Beatriz Duarte Gavião(c)}

(a) Assistant Professors, Department of Prosthetic Dentistry, School of Dentistry, Lutheran University of Brazil (Brazilian Society of Dentists, Sobracid), Porto Alegre, RS, Brazil.

(b) Professors, Department of Prosthetic Dentistry, School of Dentistry, Lutheran University of Brazil, Canoas, RS, Brazil.

(c) Professor, Department of Pediatric Dentistry, Piracicaba Dental School, State University of Campinas, Piracicaba, SP, Brazil.

\section{Corresponding author:}

Maria Beatriz Duarte Gavião

Faculdade de Odontologia de Piracicaba UNICAMP

Departamento de Odontologia Infantil

Área de Odontopediatria

Av. Limeira, 901

Piracicaba - SP - Brazil

CEP: 13414-903

E-mail:mbgaviao@fop.unicamp.br

Received for publication on Feb 28, 2007

Accepted for publication on Jul 23, 2007

\begin{abstract}
The present article aimed to present a standardized protocol for the production of a chewable test material that has been used in masticatory efficiency and performance studies. This chewable material has advantages in respect to its physical properties when compared to other artificial and natural test foods. It is constituted by mixing condensation silicon ( $58.3 \%$ by weight), common plaster ( $10.2 \%$ by weight), alginate ( $12.5 \%$ by weight), solid vaseline $(11.5 \%$ by weight), tooth paste $(7.5 \%$ by weight), and catalyst paste $(20.8 \mathrm{mg} / \mathrm{g})$, adding also three drops of mint essence. The mixed material is then inserted into an acrylic mould with perforations of $12 \mathrm{~mm}$ in diameter and $5 \mathrm{~mm}$ in height to produce rounded tablets with those measures after polymerization. It was named “Optocal - Brazilian version”. A volume of $3 \mathrm{~cm}^{3}$ is indicated for a chewing test, which corresponds to 12 tablets using the present methodology. The present protocol can make the production of this chewable material easier, helping in its standardization for studies on masticatory function.
\end{abstract}

Descriptors: Mastication; Dental materials; Recovery of function. 


\section{Introduction}

Mastication is a process in which pieces of food are ground into a fine state, mixed with saliva, and brought to approximately body temperature in readiness for the digestion. ${ }^{1}$ Pulverization of food is the main function of mastication, but it also imparts enjoyable sensations that fill a basic human need. ${ }^{1}$ Nonetheless, many studies have been conducted to investigate masticatory function objectively (masticatory performance), using artificial and nonfood test materials instead of natural foods, ${ }^{2}$ taking into account that no instrumental food hardness characterization can simulate the oral process during mastication. ${ }^{3}$ Natural foods that are most preferred by the authors are: peanuts, almonds, cocoa, carrots, jelly, hazelnuts, decaffeinated coffee beans and nuts. ${ }^{2,4-7}$ The mechanical properties of natural food could change even within the first $0.2-0.3 \mathrm{~s}$ of the first chew as an effect of the oral environment. ${ }^{8}$ Masticatory performance can determine an individual's capacity to grind or pulverize a chewable test material, artificial or natural, and results from a complex interplay of direct and indirect effects, as the number of functional tooth units, muscle (bite), ${ }^{9}$ and by the size of the area and the occlusal surface of these teeth. Therefore, masticatory function is reduced in people who have lost post-canine teeth ${ }^{4,10}$ and in those who wear removable dentures. ${ }^{5,11-13}$

Condensation silicone has been used in masticatory tests with excellent results., ${ }^{414-18}$ The silicone samples fulfill all the criteria of a test material. Namely, it is stable, accurate, reproducible, and has mechanical properties that are comparable with those of natural food substances. ${ }^{14,15}$ The test materials do not dissolve in water or saliva and can be broken down during mastication. They do not break along predetermined fault lines and have no taste. They are standardized and can be stored without losing their properties. The only constraint to their use is that the polymers cannot be digested and must not be swallowed. Therefore they cannot be used in studies of the entire mastication process from incising to swallowing. Otherwise, silicone samples may be masticated in a way which is similar to how a natural food is maticated. ${ }^{14,15}$
Optosil ${ }^{\circledR}$ has been largely applied, but it is a material with a fracture strength that is too high in comparison to the maximum bite force of subjects with compromised oral conditions, such as denture wearers. Consequently, an experimental chewable material (Optocal), having Optosil $\mathrm{NF}^{\circledR}$ as a base and mixed with other components was developed and its force-deformation properties were compared with those of Optosil ${ }^{\circledR} .^{13,19}$ Optocal appeared to be much weaker, less elastic and less resistant to deformation. It appears to be well suited for measuring masticatory performance in complete denture wearers as well as in dentate subjects. In the experience of complete denture wearers, Optocal was much easier to chew than Optosil ${ }^{\circledR}$ and they judged its texture to be comparable with that of natural foods they normally consumed. ${ }^{13,17}$ Nowadays, a new, improved version of this chewable material has been used. ${ }^{11,20}$

Masticatory efficiency and performance tests are important for the evaluation of prosthetic rehabilitation success and patient satisfaction in respect to their masticatory functions. ${ }^{12,16}$

Considering the increase in Brazilian objective studies on masticatory function, the aim of the present study was to present a standardized laboratory production protocol for producing a chewable test material, based on previous studies ${ }^{11,14,20}$, using components easily found in the Brazilian marketplace.

\section{Material and Methods Chewable test material preparation}

The proposed Brazilian version of the chewable test material, using a condensation silicon as a base, consists of a mixture of dental materials supplied in the Brazilian marketplace, using the same proportions of the current version of Optocal Plus, ${ }^{20}$ as demonstrated in Chart 1 and Figure 1.

Each material should be separately weighed in an analytical scale with a $10^{-4}$ precision (Adventure ${ }^{\mathrm{m}}$ Ohaus, Ohaus Corporation, Pine Brook, NJ, USA) at the exact proportion for the total desired amount of each components, so that the established proportions are not altered..$^{11,20}$

The catalyst paste is mixed at the proportion of $20.8 \mathrm{mg} / \mathrm{g}$ of condensation silicon (dense portion). The ideal situation is that the amount of $10 \mathrm{~g}$ is not 
Chart 1 - Components, trademarks, and percentages by weight of the silicon-based chewable test material of the present study.

\begin{tabular}{|l|l|c|}
\hline \multicolumn{1}{|c|}{ Components } & \multicolumn{1}{c|}{ Trademark } & Percentage by weight \\
\hline Condensation silicon & Optosil Comfort ${ }^{\circledR}$, Heraeus Kulzer GmbH \& Co., KG, Germany & $58.3 \%$ \\
\hline Conventional tooth paste & Colgate-Palmolive, Co., Osasco-SP, Brazil & $7.5 \%$ \\
\hline Solid vaseline & Rioquímica, São José do Rio Preto, SP, Brazil & $11.5 \%$ \\
\hline Common powder of dental plaster & Mossoró ${ }^{\circledR}$, Empresa e Indústria Gesso Mossoró SA, Rio de Janeiro, RJ, Brazil & $10.2 \%$ \\
\hline Alginate powder & Jeltrate $^{\circledR}$, Dentsply Indústria e Comércio Ltda., Petrópolis, RJ, Brazil & $12.5 \%$ \\
\hline Mint essence & Yod Comércio de produtos naturais LTDA., Campinas, SP, Brazil $^{3}$ drops \\
\hline
\end{tabular}
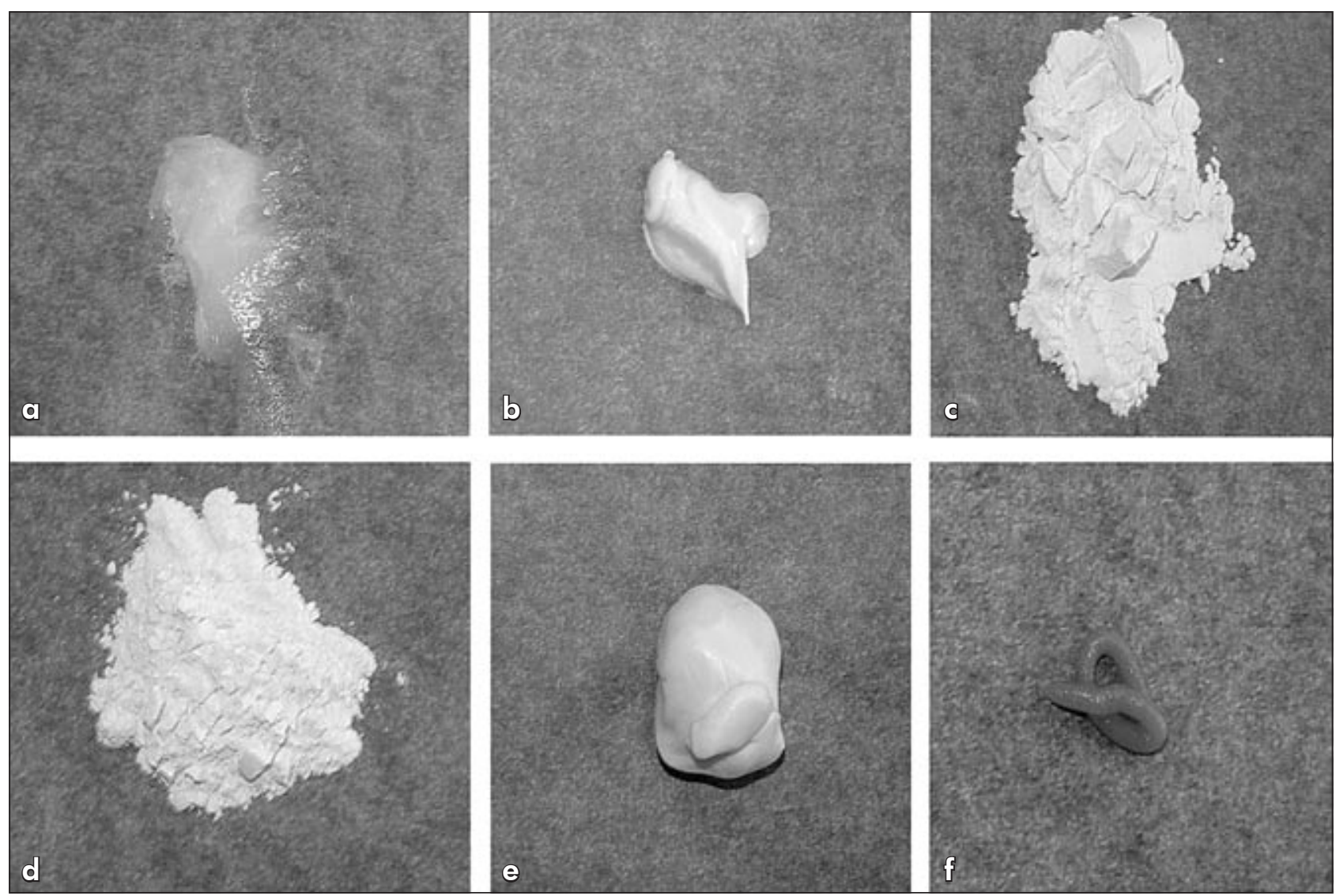

Figure 1 - Components of the chewable test material of the present study: (a) solid vaseline, (b) tooth paste, (c) alginate powder, (d) dental plaster, (e) Optosil and (f) catalyst paste; these components are mixed with three drops of mint essence.

exceeded at the moment of preparation due to the difficulty in achieving a complete homogenization of the used products as well as to the quick setting time of Optosil ${ }^{\circledR}$ after mixture with the catalyst paste. The products are dispensed onto a ceramics mortar in the following order: solid vaseline, tooth paste, common plaster, alginate powder, Optosil ${ }^{\circledR}$, and, lastly, the catalyst paste. This order makes the mixing of the materials easier, yielding a more homogenous mixture. Three drops of mint essence were added to each $10 \mathrm{~g}$ of the prepared chewable test material, intending to make it more pleasant to be chewed. Optosil ${ }^{\circledR}$ was rigorously prepared according to the manufacturer's recommendations. ${ }^{14}$ 
An acrylic resin matrix was selected, having 600 holes perforated in the shape of little cylinders, with $12 \mathrm{~mm}$ in diameter and $5 \mathrm{~mm}$ in height (Figure 2). This matrix is called encapsulator number zero (Central Laboratory of the Lutheran University of Brazil, Canoas, RS, Brazil) (Figure 2), and it functions as a standardized mold for the confection of tablets measuring $12 \mathrm{~mm}$ in diameter and $5 \mathrm{~mm}$ in height (Figure 3).

After homogenization of the dental materials, insertion of the mixed components is initiated into the matrix perforations. Due to the quick polymerization of Optosil ${ }^{\circledR}$, which happens a few minutes after mixing with the catalyst paste, it is recommended that only $10 \mathrm{~g}$ of the mixed components be prepared

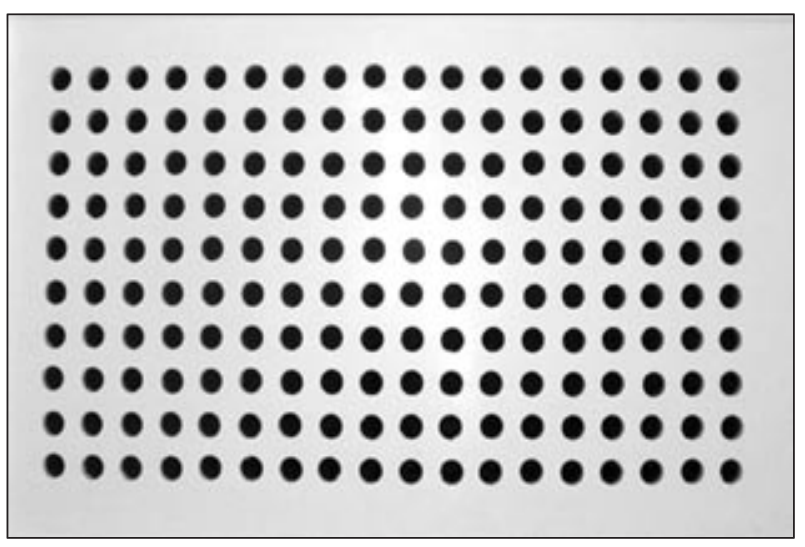

Figure 2 - Encapsulator number zero.

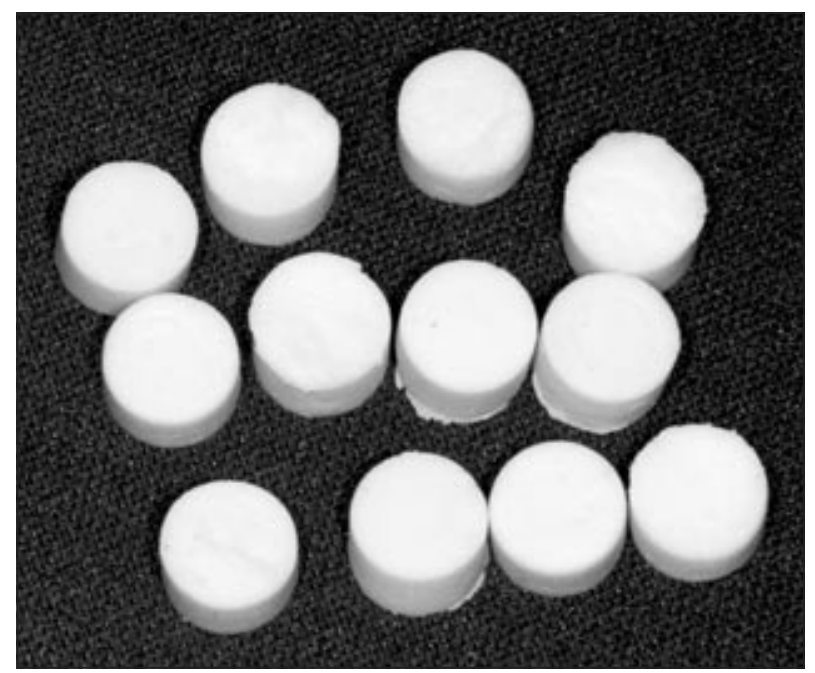

Figure 3 - Tablets: $12 \mathrm{~mm}$ in diameter and $5 \mathrm{~mm}$ in height (12 tablets, $\left.3 \mathrm{~cm}^{3}\right)$. each time, which represent approximately 34 tablets. Nonetheless, to retard the polymerization, Optosil ${ }^{\circledR}$ can be stored in a refrigerator during 6 hours before use. After material insertion, excess material must be removed with a plastic spatula, and 15 minutes must be waited before removing the tablets from the encapsulator, in order to guarantee the polymerization and prevent any deformation. ${ }^{14}$ With the aid of a glass stick, compatible with the diameter of the perforations, the samples are removed from the tray and taken directly to an oven during 16 hours at $65^{\circ} \mathrm{C}$ to allow a complete polymerization cycle. ${ }^{19}$

\section{Results}

After the procedures described above, the artificial chewable test material is ready to be used (Figure 3), and it was named "Optocal - Brazilian version". It is recommended that any functional test be performed up to 7 days after polymerization to guarantee dimensional stability of the condensation silicon.

Evaluation of masticatory performance was carried out as reported by Pocztaruk ${ }^{12}$ (2006), using 12 tablets corresponding to $3 \mathrm{~cm}^{3}$, a volume that an individual would normally be able to chew. ${ }^{16-18,20,21}$ Thus, considering the tablet measurements in this protocol , 12 tablets of Optocal - Brazilian version are recommended for masticatory tests. The tablets should be chewed for a determined number of cycles or during a specified time, depending on the aim of the study, and then spat out. The resulting particles and the degree of material breakdown can be determined by sieving or by optical methods [for more details see Gambareli et al. ${ }^{2}$ (2007); Albert et al. ${ }^{14}$ (2003); van der Bilt, Fontijn-Tekamp ${ }^{21}$ (2004)].

\section{Discussion}

There are several methods for the evaluation of masticatory efficiency and performance. ${ }^{15}$ Some tests described in the literature use natural foods as a material test, using one or more bolters for measuring the comminution power of that patient. ${ }^{4,5}$ Physical properties of natural foods vary and are difficult to standardize. There are variations in food shape, size, and hardness, which produce differences in the tests, thus influencing the final results. ${ }^{17}$ Besides, 
they vary in consistency, due to water incorporation from saliva, making the standardization for the accomplishment of masticatory tests difficult. ${ }^{14}$ For this reason, use of a condensation silicon was proposed $^{15}$ as an artificial chewable test material for evaluation of masticatory function. Optosil ${ }^{\circledR}$, or other condensation silicon trademark, ${ }^{14}$ has the quality of being almost odorless and tasteless, not incorporating water, and being able to be kept for up to 7 days without suffering any important dimensional alterations. Samples of this elastomeric material can be easily standardized and assessed after chewing, allowing weight and size control, thus reducing variability during production and during masticatory tests. However, it has been observed that patients wearing full dentures, who are already impaired in terms of bite strength, ${ }^{4,22}$ present chewing difficulties when the test material is solely based on Optosi $1^{\circledast}$ due to its hardness. ${ }^{14}$ Such patients eventually strain their masticatory muscles in an effort to chew it. ${ }^{13}$ This test food, which possesses a much higher resistance against fracture than the maximum bite strength capacity of the patients themselves, would impair the reliability of the quantification of masticatory efficiency and performance. For this reason, other dental materials have been added to Optosil ${ }^{\circledR}$, allowing a decrease in consistency, making it easier to be chewed. With this purpose, Optocal was developed. ${ }^{13}$ It was later improved by using Optosil plus ${ }^{\circledR}$ (Bayer Dental, Leverkusen, Germany, version 1997) and by changing the component proportions (Optocal plus). ${ }^{11,20}$

Association to other dental components makes the initial test material less resistant to fracture and easier to be comminuted by wearers of removable partial prostheses and conventional full den-

\section{References}

1. Bourne MC. Relation between texture and mastication. J Texture Stud. 2004;35(2):125-43.

2. Gambareli FR, Serra MD, Pereira LJ, Gaviao MB. Influence of measurement technique, test food, teeth and muscle force interactions in masticatory performance evaluation. Review Article. J Texture Stud. 2007;38(1):2-20.

3. Heath MR, Lucas PW. Mastication: the need for collaborative research. J Texture Stud. 1987;18(2):111-23. tures, as well as by those with implants and overdentures. ${ }^{18,20}$ In terms of consistency, it is similar to natural foods. ${ }^{19}$ Therefore, considering the reliable results found in the literature, ${ }^{11,12,18-21}$ it seems to be appropriate for the accomplishment of masticatory tests with more trustworthy results in the distribution of the amount of comminuted material. The difficulty in obtaining an adequate artificial chewable test material by using the materials available in the Brazilian dental marketplace and the observed increase in studies on masticatory function in Brazil (personal observation) led us to put forward this procedure for the production of Optocal - Brazilian version. Its advantages may be attributed to easiness of production, low cost, resemblance to natural foods, ${ }^{13}$ and mainly to the comfort that it represents for individuals that have been submitted to masticatory performance testing. ${ }^{12}$ On the other hand, advances in the development of dental materials and marketplace changes related to the withdrawal and introduction of new products must be taken in consideration when a chewable material is produced. The physical properties of the new components must be similar to those of the original ones, ${ }^{13,14,20}$ which have given reliable results, as mentioned above, regardless of the tablet formats. ${ }^{10,11,13,15,18}$

\section{Conclusions}

The production of Optocal - Brazilian version was considered simple and adequate due to the use of Brazilian dental materials, low cost, and simple equipment requirements. It was considered adequate for the standardization of a test material for studies on the masticatory function in healthy individuals as well as in prosthodontic patients.

4. Helkimo E, Carlsson GE, Helkimo M. Chewing efficiency and state of dentition. A methodologic study. Acta Odontol Scand. 1978;36(1):33-41.

5. Kapur KK, Soman SD. Masticatory performance and efficiency in denture wearers. 1964. J Prosthet Dent. 2006;95(6):40711.

6. Kimoto K, Garrett NR. Effect of mandibular ridge height on masticatory performance with mandibular conventional and 
implant-assisted overdentures. Int J Oral Maxillofac Implants. 2003;18(4):523-30.

7. Schneider G, Senger B. Clinical relevance of a simple fragmentation model to evaluate human masticatory performance. J Oral Rehabil. 2002;29(8):731-6.

8. Kohyama K, Nishi M. Direct measurement of biting pressures for crackers using a multiple-point sheet sensor. J Texture Stud. 1997;28(6):605-17.

9. Hatch JP, Shinkai RS, Sakai S, Rugh JD, Paunovich ED. Determinants of masticatory performance in dentate adults. Arch Oral Biol. 2001;46(7):641-8.

10. van der Bilt A, Olthoff LW, Bosman F, Oosterhaven SP. The effect of missing postcanine teeth on chewing performance in man. Arch Oral Biol. 1993;38(5):423-9.

11. Fontijn-Tekamp FA, Slagter AP, van der Bilt A, van't Hof MA, Witter DJ, Kalk W et al. Biting and chewing in overdentures, full dentures, and natural dentitions. J Dent Res. 2000;79(7):1519-24.

12. Pocztaruk RL. Avaliação do nível de satisfação, da capacidade, eficiência e performance mastigatória em pacientes reabilitados com próteses totais convencionais e sobre implantes [Dissertação de Mestrado]. Canoas: Faculdade de Odontologia da Universidade Luterana do Brasil; 2006.

13. Slagter AP, Bosman F, Van der Bilt A. Comminution of two artificial test foods by dentate and edentulous subjects. J Oral Rehabil. 1993;20(2):159-76.
14. Albert TE, Buschang PH, Throckmorton GS. Masticatory performance: a protocol for standardized production of an artificial test food. J Oral Rehabil. 2003;30(7):720-2.

15. Edlund J, Lamm CJ. Masticatory efficiency. J Oral Rehabil. 1980;7(2):123-30.

16. Pera P, Bassi F, Schierano G, Appendino P, Preti G. Implant anchored complete mandibular denture: evaluation of masticatory efficiency, oral function and degree of satisfaction. $\mathrm{J}$ Oral Rehabil. 1998;25(6):462-7.

17. Slagter AP, Olthoff LW, Steen WH, Bosman F. Comminution of food by complete-denture wearers. J Dent Res. 1992;71(2):380-6.

18. van Kampen FM, van der Bilt A, Cune MS, Fontijn-Tekamp FA, Bosman F. Masticatory function with implant-supported overdentures. J Dent Res. 2004;83(9):708-11.

19. Slagter AP, van der Glas HW, Bosman F, Olthoff LW. Forcedeformation properties of artificial and natural foods for testing chewing efficiency. J Prosthet Dent. 1992;68(5):790-9.

20. Fontijn-Tekamp FA, Slagter AP, van der Bilt A, Van't Hof MA, Kalk W, Jansen JA. Swallowing thresholds of mandibular implant-retained overdentures with variable portion sizes. Clin Oral Implants Res. 2004;15(3):375-80.

21. van der Bilt A, Fontijn-Tekamp FA. Comparison of single and multiple sieve methods for the determination of masticatory performance. Arch Oral Biol. 2004;49(2):155-60.

22. Michael CG, Javid NS, Colaizzi FA, Gibbs CH. Biting strength and chewing forces in complete denture wearers. J Prosthet Dent. 1990;63(5):549-53. 